\title{
Association of Trace Metals in Patients with Schizophrenia
}

\author{
Muhammad Hamid Awais ${ }^{1}$, Muhammad Aamir ${ }^{1}$, Afshan Bibi ${ }^{1}$, Sohail Ali ${ }^{2}$, Waqas Ahmed ${ }^{2}$ \\ and Sachal Aqeel Safdar ${ }^{2}$ \\ ${ }^{1}$ Department of Chemical Pathology and Endocrinology, Armed Forces Institute of Pathology (AFIP), Rawalpindi, Pakistan \\ ${ }^{2}$ Armed Forces Institute of Mental Health (AFIMH), Rawalpindi, Pakistan
}

\begin{abstract}
Objective: To compare the serum concentrations of copper, iron and zinc in schizophrenic patients with healthy individuals. Study Design: Cross-sectional comparison study.

Place and Duration of Study: Department of Chemical Pathology and Endocrinology, Armed Forces Institute of Pathology (AFIP), Rawalpindi, Pakistan. The study was conducted from July to December 2020.

Methodology: Among 115 participants in the study, schizophrenic patients and healthy subjects were 35 and 80, respectively. Copper and zinc were measured by using atomic absorption spectrophotometry. Serum Iron measurement was done on ADVIA 1800 chemistry auto analyser. Comparison of these trace metals among patients with schizophrenia and healthy subjects, by using Mann-Whitney U-test and correlation with the duration of disease, was analysed by the application of Spearman's correlation.

Results: Males accounted for $25(71.4 \%)$ and females were 10 (28.6\%) in diseased group; while in healthy subjects, males accounted for $54(67.5 \%)$ and females $26(32.5 \%)$. Copper, iron and zinc levels were noted to be significantly reduced in schizophrenic patients, when compared with healthy subjects $(p<0.001)$.

Conclusion: This study could offer an additional clue in the diagnosis and possible role of trace metals in pathophysiology and progression of many psychiatric illnesses, particularly schizophrenia.
\end{abstract}

Key Words: Psychiatric illness, Schizophrenia, Trace metals.

How to cite this article: Awais MH, Aamir M, Bibi A, Ali S, Ahmed W, Safdar SA. Association of Trace Metals in Patients with Schizophrenia. J Coll Physicians Surg Pak 2022; 32(02):193-196.

\section{INTRODUCTION}

Schizophrenia is a mental disorder, which can be characterised by impairment in behaviour, judgment, and inability to interpret the reality along with significant morbidity, and ultimately leading to mortality. ${ }^{1-3}$ About $1 \%$ of the world total population and $1.5 \%$ population of Pakistan is affected ${ }^{4,5}$ Men and women are equally affected, and usual age for presentation of symptoms is 15-40 years. Risk factors include genetic predisposition, child birth in winter, prenatal infection, perinatal complications, poor living standards, auto-immune, and viral infections. ${ }^{6-8}$ Despite apparent developments in understanding epidemiology, genetics and neurobiology of schizophrenia, the exact mechanism causing development of this disease, still remains unknown. ${ }^{9}$

Correspondence to: Dr. Muhammad Hamid Awais, Department of Chemical Pathology and Endocrinology, Armed Forces Institute of Pathology (AFIP), Rawalpindi, Pakistan E-mail: awaismangat@gmail.com

Received: July 05, 2021; Revised: November 05, 2021; Accepted: December 06, 2021

DOI: https://doi.org/10.29271/jcpsp.2022.02.193
However, evidence from previous studies have imparted an important role of trace metals in the pathophysiology of schizophrenia. ${ }^{10}$ Many trace metals take part in metabolic reactions and some act as antioxidants. Brain is considered to be highly vulnerable organ to oxidative stress as it is major organ consuming about $25 \%$ of total oxygen of human body. ${ }^{11}$ Oxidative stress is produced as a result of an imbalance between antioxidant levels and the cellular production of reactive oxygen species (ROS). Majority of mental disorders are considered to be associated with oxidative stress. ${ }^{12,13}$

It has been suggested that a change in trace metal levels are associated with the pathophysiology and etiology of various psychiatricillnesses, including schizophrenia. ${ }^{6,14,15}$

Levels of essential trace metals like $\mathrm{Cu}, \mathrm{Zn}$ and Fe have been evaluated by various studies in schizophrenia. Some patients have associated imbalance of these metals with the progression of schizophrenia; ${ }^{7}$ while others have shown a negative correlation, and some have found no difference at all. ${ }^{3}$ Paucity of literature in general Pakistani population impelled the authors to perform this study in the local community.

The objective of this study was to compare the serum concentrations of copper, iron and zinc in schizophrenic patients with 
healthy individuals in a tertiary care hospital to find outanyassociation of these trace metals with schizophrenia.

\section{METHODOLOGY}

A cross-sectional, comparison study was conducted from July to December 2020, after taking prior approval of the Institution's Ethical Review Board. Individuals diagnosed patients of schizophrenic with age group 15-55 years of both gender, who met diagnostic and statistical manual of mental disorders-IV (DSMIV) criteria for the schizophrenia, were included. Patients with history of drug abuse, other psychiatric illnesses, severe head injury or seizures, chronic organic diseases and cancers, were excluded from thestudy, which can interfere with the concentration of these trace metals. The participants were interviewed by a team of psychiatrists, at the time of collection of samples; and information was obtained regarding their age, socio-economic status, family background, and family and past medical history. Information regarding smoking, chronic illness, drug intake and alcohol consumption were obtained by questionnaires. Age and gender-matched 80 healthy individuals with no personal or family history of any mental illness, participated in this study as control.

Both controls and patients were enrolled during the same period and informed written consent was taken prior to sampling. $5 \mathrm{ml}$ venous blood was drawn into gel tubes and centrifuged for 5 minutes at 3000 RPM. After removing serum, it was stored at $-20^{\circ} \mathrm{C}$ immediately. $\mathrm{Cu}$ and $\mathrm{Zn}$ were measured by using atomic absorption spectrophotometry, while Fe measurement was done on chemistry auto analyser ADVIA 1800.

By using SPSS version 26.0, data were analysed. Shapiro-Wilk test was used to check the normality of data. For numerical variables, median (IQR) was calculated. For categorical variables, frequencies and percentages were calculated. Comparison between cases and controls was done by Mann-Whitney U-test. Spearman's correlation was used to analyse correlation between various trace metals and schizophrenia, while considering $p$ value $\leq 0.05$ to be significant.

\section{RESULTS}

Out of 115 participants, 35 (30.4\%) were diagnosed cases of schizophrenia and 80 (69.6\%) were healthy subjects, as controls. Males accounted for $25(71.4 \%)$ and females were $10(28.6 \%)$ in patients; and in healthy subjects, males accounted for 54 (67.5\%) and females $26(32.5 \%)$. Median (IQR) age of the patients was 33 (30-44) years. Median duration of the disease was 1.5 (1.2-2.0) years. Median levels of $\mathrm{Cu}, \mathrm{Zn}$ and Fe were found to be lower in schizophrenic patients as compared to healthy subjects $(p<0.05)$ (Tablel).

Using Spearman'scorrelation, a negativecorrelation in concentrations of $\mathrm{Cu}(r=-0.833, p<0.001) \mathrm{Zn}(r=-0.483, \mathrm{p}=0.003)$ and $\mathrm{Fe}$ $(r=-0.500, p=0.002)$ with the disease duration was seen.

Male to female ratio and median values of $\mathrm{Cu}, \mathrm{Zn}$ and Fe have been compared with national and international studies, and summarised in Tablell.
Table I: Levels of serum trace metals in schizophrenics and healthy individuals.

\begin{tabular}{|c|c|c|c|}
\hline & \multicolumn{2}{|c|}{ Median (IQR: $25^{\text {th }}-75^{\text {th }}$ percentiles) } & \multirow[b]{2}{*}{$p$-value } \\
\hline & $\begin{array}{l}\text { Schizophrenics } \\
\quad(n=35)\end{array}$ & $\begin{array}{l}\text { Healthy Individuals } \\
(\mathrm{n}=80)\end{array}$ & \\
\hline $\begin{array}{l}\text { Copper (Cu) } \\
\text { umol/L }\end{array}$ & $13.6(12.2-15.5)$ & $19.32(17.60-20.71)$ & $<0.001$ \\
\hline $\begin{array}{l}\text { Zinc } \\
\text { (Zn)umol/L }\end{array}$ & $11(9.9-11.8)$ & $16.15(15.41-17.15)$ & $<0.001$ \\
\hline Iron (Fe)umol/L & $11.26(10.54-12.79)$ & $22.33(18.71-24.43)$ & $<0.001$ \\
\hline
\end{tabular}

\section{DISCUSSION}

Trace metals are needed for the optimal functioning of central nervous system (CNS) as these metals act as regulators of gene expression and second messengers. In the humans, these metals are ingested through water, food, air or may be absorbed through the skin, which reach brain through blood brain barrier. ${ }^{5}$

Some, such as copper $(\mathrm{Cu})$, zinc $(\mathrm{Zn})$ and iron $(\mathrm{Fe})$ catalyse reactions that are involved in metabolism, chemical detoxification, cellular respiration and neuro-transmitter synthesis. ${ }^{16}$

The imbalance of copper may cause fatigue, insomnia and depression. Copper excess is also considered to cause emotional instability; and it is found in many hyperactive children. It can lead to depression without any known cause. ${ }^{17}$ Zinc is found mostly in hippocampus, and it can cause impairment in learning and memory, and is related to RNA and DNA synthesis. ${ }^{18}$ Iron is essential for the normal functioning of neuronal tissues. CNS disorders can occur, if excess Fe is accumulated in brain. ${ }^{19}$ Many researchers have also found abnormal deposits of iron in the brain of schizophrenic patients. ${ }^{17}$

Cu has an important part to play in the pathogenesis of schizophrenia. It plays a significant role in the production of oxidative stress. In this study, Cu levels were significantly decreased in schizophrenics patient (13.6, 12.2-15.5 umol/L) as compared to the healthy group $(19.32,17.60-20.71 \mathrm{umol} / \mathrm{L})$. About copper, there are variable accounts in the patients with psychiatric illnesses as it has shown both raised and depressed levels in schizophrenia. This result is consistent with the study done by Liu etal. with 114 participants, each in case and control groups; which found $\mathrm{Cu}$ to be decreased among schizophrenic patients. ${ }^{6}$ However, in a more recent study, Cu was higher among patients with major depressive disorder (MDD); but Zn levels were decreased, thereby establishing a crucial $\mathrm{Cu} / \mathrm{Zn}$ ratio. ${ }^{1}$ In a study done in 2014 , increased $\mathrm{Cu}$ levels were found in schizophrenic patients as compared to control groups. ${ }^{7}$

$\mathrm{Zn}$ is an essential elements, which is required for the developmentand normal functioning ofCNS. Zn deficiency has been associated with abnormalities in cognitive development, resulting in changes in attention, activity, neuro-psychological behaviours and motor development. Schizophrenic patients have shown decreased $Z n$ concentrations as compared to the healthy individuals $(p<0.001)$, in this study. Similar to the present observations, a recent analysis has also reported reduced $\mathrm{Zn}$ levels in schizophrenics as compared to healthy controls. ${ }^{1}$ 
Table II: Comparison of gender and means of trace metals with other studies.

\begin{tabular}{|l|l|c|c|c|c|}
\hline \multicolumn{2}{|c|}{} & Male/Female Ratio & Copper umol/L (Median/IQR) & Zinc umol/L (Median/IQR) & Iron umol/L (Median/IQR) \\
\hline \multirow{2}{*}{ Present study } & Cases & $25 / 10$ & $13.6(12.2-15.5)$ & $11.0(9.9-11.8)$ & $11.26(10.54-12.79)$ \\
\cline { 2 - 6 } & Control & $54 / 26$ & $19.32(17.60-20.71)$ & $16.15(15.41-17.15)$ & $22.33(18.71-24.43)$ \\
\hline \multirow{2}{*}{ Nawaz et al. ${ }^{5}$} & Cases & $22 / 13$ & $5.99(2.53-14.31)$ & $10.8(8.55-19.57)$ & $10.6(6.14-12.64)$ \\
\cline { 2 - 6 } & Control & $12 / 8$ & $4.36(0.86-12.07)$ & $9.69(7.09-21.77)$ & $11.56(8.58-16.29)$ \\
\hline \multirow{2}{*}{ Cao B et al. ${ }^{1}$} & Cases & $44 / 61$ & $13.37(12.11-16.05)$ & $13.45(11.62-14.98)$ & $23.45(19.51-27.03)$ \\
\cline { 2 - 6 } & Control & $38 / 68$ & $13.06(11.17-14.94)$ & $13.76(11.77-16.82)$ & $20.77(17.19-25.24)$ \\
\hline
\end{tabular}

Fe has an essential role to play in routine functioning at cellular level, in the synthesis of DNA and neurotransmitters; and this has been demonstrated by the ability of Fe to act as a coenzyme in oxygenation of neuro-transmitters. ${ }^{1}$ Research has also suggested role of $\mathrm{Fe}$ in the cognition and brain development. ${ }^{20,21}$ This study has revealed decreased level of $\mathrm{Fe}$ in the schizophrenic patients. This is in keeping with previous data regarding lower iron levels in patients compared to controls. ${ }^{22}$ Lower Fe levels in schizophrenics have been reported, and possible effects of Fe deficiency on dopaminergic system have been demonstrated. ${ }^{15}$

There could be a possible role of these metallic biomarkers in the etiology and further treatment of schizophrenia. Decrease in the concentrations of $\mathrm{Cu}, \mathrm{Zn}$ and Fe can be taken as a potential future tool for the diagnosis of neuropsychiatric disorders. Further research with a multi-centric approach and larger sample size is needed in order to find out concentrations of these trace metals in Schizophrenia and other disorders.

\section{CONCLUSION}

Decreased levels of serum $\mathrm{Cu}, \mathrm{Fe}$ and $\mathrm{Zn}$ were noted in patients with schizophrenia as compared to the healthy controls. Further research of a higher magnitude should be undertaken for evaluation of these biomarkers in the serum, plasma, CSF and urine. This study could be an advancement in the diagnosis and differentiation of many psychiatric illnesses, particularly schizophrenia.

\section{DISCLOSURE:}

All the patients were army personnel or dependents of army personnel, who are entitled patients. Facility for these tests is already available at Armed Forces Institute of Pathology for entitled patients.

\section{ETHICAL APPROVAL:}

Ethical approval was taken from Ethical Committee of Armed Forces Institute of Pathology before the start of research work.

\section{PATIENTS' CONSENT:}

Written consents were taken from all the participants of the study.

\section{CONFLICT OF INTEREST:}

The authors declared no conflict of interest.

\section{AUTHORS' CONTRIBUTION:}

MHA: Data collection, data analysis, results, discussion and literature review.

MA: Data analysis, results, discussion and literature review.

$A B$ : Results, discussion and literature review.

SA, SAS: Discussion and literature review.

WA: Results and literature review.

\section{REFERENCES}

1. Cao B, Yan L, Ma J, Jin M, Park C, Nozari Y, et al. Comparison of serum essential trace metals between patients with schizophrenia and healthy controls. J Trace Elem Med and Biol 2019; 51:79-85. doi: 10.1016/j.jtemb.2018.10.009.

2. Strassnig M, Signorile J, Gonzalez C, Harvey PD. Physical performance and disability in schizophrenia. Schizophr Res Cogn 2014; 1(2):112-21. doi: 10.1016/j.scog.2014.06.002.

3. Green MF, Horan WP, Lee J. Social cognition in schizophrenia. Nat Rev Neurosci 2015; 16(10):620-31. doi: 10.1038/nrn4005.

4. Santa Cruz EC, Madrid KC, Arruda MA, Sussulini A. Association between trace elements in serum from bipolar disorder and schizophrenia patients considering treatment effects. J Trace Elem Med Biol 2020; 59:126467. doi: 10.1016/j.jtemb.2020.126467.

5. Nawaz R, Zahir E, Siddiqui S, Usmani A, Shad KF. The role of trace metals and environmental factors in the onset and progression of schizophrenia in Pakistani population. World J Neurosci 2014; 4(5):450-60.

6. Liu T, Lu QB, Yan L, Guo J, Feng F, Qiu J, et al. Comparative study on serum levels of 10 trace elements in schizophrenia. PLoS One 2015; 10(7):e0133622. doi: 10. 1371/journal.pone.0133622.

7. Tandon R, Keshavan MS, Nasrallah HA. Schizophrenia, “just the facts" what we know in 2008. 2. Epidemiology and etiology. Schizophr Res 2008; 102(1-3):1-18. doi: 10.1016/j.schres.2008.04.011.

8. Réthelyi JM, Benkovits J, Bitter I. Genes and environments in schizophrenia: The different pieces of a manifold puzzle. Neurosci Biobehav Rev 2013; 37(10):2424-37. doi: 10.1016/j.neubiorev.2013.04.010.

9. Benros ME, Mortensen PB, Eaton WW. Autoimmune diseases and infections as risk factors for schizophrenia. Ann NY Acad Sci 2012; 1262(1):56-66. doi: 10.1111/j.17496632.2012.06638.x.

10. Vidović B, Đorđević B, Milovanović S, Škrivanj S, Pavlović Z, Stefanović $A$, et al. Selenium, zinc, and copper plasma levels in patients with schizophrenia: relationship with metabolic risk factors. Biolo Trace Elem Res 2013; 
156(1):22-8. doi: 10.1007/s12011-013-9842-1.

11. Al-Fartusie FS, Al-Bairmani HK, Al-Garawi ZS, Yousif AH. Evaluation of some trace elements and vitamins in major depressive disorder patients: A case-control study. Biol Trace Elem Res 2019; 189(2):412-9. doi: 10.1007/s12011-018-1507-7.

12. Salim S. Oxidative stress and psychological disorders. Curr Neuropharmacol 2014; 12(2):140-7. doi: 10.2174/1570159 X11666131120230309.

13. Tsaluchidu S, Cocchi M, Tonello L, Puri BK. Fatty acids and oxidative stress in psychiatric disorders. BMC psychiatry 2008; 8(1):1-3. doi: 10.1186/1471-244X-8-S1-S5.

14. Shohag H, Ullah A, Qusar S, Rahman M, Hasnat A. Alterations of serum zinc, copper, manganese, iron, calcium, and magnesium concentrations and the complexity of interelement relations in patients with obsessive-compulsive disorder. Biol Trace Elem Res 2012; 148(3):275-80. doi: 10.1007/s12011-012-9371-3.

15. Nechifor M, Vaideanu C, Palamaru I, Borza C, Mindreci I. The influence of some antipsychotics on erythrocyte magnesium and plasma magnesium, calcium, copper and zinc in patients with paranoid schizophrenia. J Am Coll Nutr 2004; 23(5):549S-51S. doi: 10.1080/07315724.2004.10719401.
16. Wright RO, Baccarelli A. Metals and neurotoxicology. J Nutr 2007; 137(12):2809-13.

17. Devi PU, Chinnaswamy P, Murugan S, Selvi S. Plasma levels of trace elements in patients with different symptoms of Schizophrenia. Biosci Biotech Res Asia 2016; 5(1):261-8.

18. Osredkar J, Sustar N. Copper and zinc, biological role and significance of copper/zinc imbalance. J Clinic Toxicol S 2011; 3(2161):0495.

19. Zecca L. Youdim MB, Riederer P, Connor JR, Crichton RR. Iron, brain ageing and neurodegenerative disorders. Nat Rev Neurosci 2004; 5(11):863-73. doi: 10.1038/nrn1537.

20. Larson LM, Phiri KS, Pasricha SR. Iron and cognitive development: What is the evidence? Ann Nutr Metab 2017; 71(Suppl 3):25-38. doi: 10.1159/000480742.

21. Gambling L, Kennedy C, McArdle HJ, editors. Iron and copper in fetal development. Seminars in cell \& developmental biology; 2011: Elsevier.

22. Yanik M, Kocyigit A, Tutkun H, Vural H, Herken H. Plasma manganese, selenium, zinc, copper, and iron concentrations in patients with schizophrenia. Biolo Trace Elem Res 2004; 98(2):109-17. doi: 10.1385/BTER:98:2:109. 